\title{
Improving the right stuff
}

S urgeons, like astronauts, have the right stuff. We know it and never talk about it; if you have it, you never do. People with the right stuff have few problems, and solve them themselves. The trouble is, this is a myth, and like all necessary myths, it is a powerful one. Performing surgery requires structured physical performance and emotional stress, and the stress that is produced requires some form of relief. Surgeons often choose sports - golf, skiing and any activity that offers a change from surgery. The trouble is, the problems that are created by surgery are sometimes there when we come back. Problems that occur from practising surgery are seldom related to technical performance and are more likely to be interpersonal.

The recent suicides of several model plastic surgeons have shocked our specialty, prompting anguish and questions such as, "He was my good friend, why didn't he call me to talk about it, and ask me to arrange care?"

We know how insidious depression can be and how its early stages are sometimes hidden and well compensated. I would suggest that we look into our surgical personalities as a possible cause of our problems and that the perfectionistic and obsessive-compulsive traits that can produce success, quality surgery and innovation can sometimes cause us real problems, especially in the personal arena.

To diagnose our own problems early, I recommend that we find a way to solve them before they become roadblocks, or worse. Before I suggest anything further, let me say that one's spouse or friends are essential for discussion; to help, to arrange care, and to break our 'strong, silent' mold, remembering that brittle things eventually break. Our spouses and families are wonderful support, but are sometimes not objective, and friends sometimes lack the training of other professionals who could help us.

I suggest we follow the lead of other professions by having trainer/mentors (TMs) to optimize performance and to analyze personal and practice problems before they become bigger problems. The surgeon would set up a professional relationship with the TM on a regular (monthly) basis and would discuss anything of concern. The TM would act as a sounding board for analyzing issues and would suggest courses of action that the surgeon may not have considered. Over time, a relationship would be developed for times of

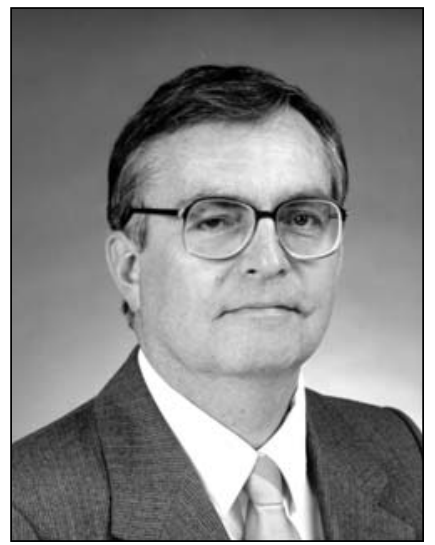

John R Taylor problem solving, established in good times, and natural to use in bad times. The TM would not be a peer, but a professional who is met with on a one-to-one basis, at the discretion of the surgeon and in an entirely confidential manner.

Professional athletes have trainers and are aware that training involves psychological conditioning for best performance. Surgeons are like athletes, because surgery involves mental and physical performance at a staged event - the operation.

I suggest that surgeons stop being strong, silent types, choose to gain insight into their surgical personalities, use discussion with a TM on a regular basis to improve performance, and problem solve the truly difficult problems we have; those within ourselves.

John R Taylor MD

Associate Editor The Canadian Journal of Plastic Surgery 